\title{
Prospecção Tecnológica de Processo de Fabricação de Próteses Articuladas a partir da Combinação de Materiais Rígidos e Flexíveis em uma Única Peça
}

\author{
Technological Prospecting of the Manufacturing Process of Articulated \\ Prostheses from the Combination of Rigid and Flexible Materials in a \\ Single Piece
}

Victor Seabra Dornas ${ }^{1}$

Alan Elvis Lima ${ }^{1}$

Magna Pinheiro Pessoa ${ }^{1}$

Lívia Pereira de Araújo ${ }^{1}$

Grace Ferreira Ghesti ${ }^{1}$

Paulo Gustavo Barboni Dantas Nascimento ${ }^{1}$

${ }^{1}$ Universidade de Brasília, Brasília, DF, Brasil

\begin{abstract}
Resumo
O presente artigo destina-se a prospectar e a avaliar um pedido de concessão de patente de uma tecnologia ortopédica baseada em método de confecção de prótese artificial cuja titularidade patrimonial pertence à Universidade de Brasília. Informa-se que se adotou neste estudo como metodologia a busca em bases de patente, bem como uma pesquisa mais abrangente sobre aspectos relacionados, como viabilidade mercadológica, para fins de deliberar acerca da manutenção ou não das taxas anuais aplicadas pelo INPI e, neste caso, custeadas pelo erário. Trata-se de uma técnica chamada FDM (Fused Deposition Modeling) destinada à impressão tridimensional das próteses articuladas para as mãos, tanto com finalidade estética como funcional. Por meio de uma análise baseada em matriz SWOT, buscou-se, portanto, uma projeção de mercado, tanto em âmbito público como no privado, ainda que sopesadas as atuais condições intermediárias observadas no grau de aferição TRL.
\end{abstract}

Palavras-chave: Prospecção. Prótese de Mão. Impressão Tridimensional.

\begin{abstract}
This article aims to prospect and evaluate a patent application for an orthopedic technology based on the method of making artificial prostheses whose property belongs to the University of Brasilia. We inform that in this study the search on patent bases was adopted as a methodology, as well as a more comprehensive research on related aspects, such as market viability, for the purpose of deliberating about the maintenance or not of the annual fees applied by the INPI and, in this case, funded by the treasury. It is a technique called FDM (Fused Deposition Modeling) for the three-dimensional printing of articulated prostheses for the hands, both for aesthetic and functional purposes. Through an analysis based on a SWOT matrix, therefore, a market projection was sought, both in the public and private spheres, even though the current intermediate conditions observed in the degree of TRL measurement were weighed.
\end{abstract}

Keywords: Prospection. Hand Prosthesis. Three-Dimensional Printing.

Área Tecnológica: Prospecção Tecnológica. 


\section{Introdução}

Entre os anos de 2008 e 2015, foram realizados pelo Sistema Único de Saúde (SUS) do Brasil 361.585 procedimentos de amputações de membros superiores e inferiores, o que representa uma média de mais de 45 mil casos por ano. Naquele período, enquanto a população do país apresentou uma taxa de crescimento populacional de $0,9 \%$, o número de amputações cresceu em média 3,8\% (PEIXOTO et al., 2017).

O alto custo de órteses e próteses, aliado ao quantitativo anual utilizado, levou o Ministério da Saúde a lançar em 2018 uma licitação para registro de preços, com o objetivo de referenciar o valor para compra desse tipo de produto em apoio ao SUS. A medida também tem por objetivo coibir variações de preços, entre os estados, que podem chegar até $990 \%$ na aquisição desses produtos pela rede de saúde (BRASIL, 2018).

Pelo lado da oferta, o panorama mundial aponta para um mercado forte e concentrado: o mercado mundial para os produtos Equipamentos e Materiais Médicos, Hospitalares e Odontológicos (EMHO), do qual o segmento de Órteses e Próteses (O\&P) faz parte, gerou um faturamento da ordem de US\$ 375 bilhões em 2014, com projeção para chegar a US 477 bilhões em 2020 (ABDI, 2014).

O Brasil iniciou sua participação no esforço mundial para o desenvolvimento de tecnologias relacionadas ao setor há vários anos. No período de 1984 a 1995, por exemplo, foram registrados no Instituto Nacional da Propriedade Industrial (INPI) quatro pedidos de patentes relacionadas a Próteses não implantáveis no corpo (EPSZTEJN, 2008). Em iniciativa mais recente, em 27 de novembro de 2014, foi realizado o depósito de patente número BR 102014029649-2, 27/11/2014, sob o título "PROCESSO DE FABRICAÇÃO DE PRÓTESES ARTICULADAS A PARTIR DA COMBINAÇÃO DE MATERIAIS RÍGIDOS E FLEXÍVEIS EM UMA ÚNICA PEÇA”. Esse invento trata da impressão tridimensional, pelo método Fused Deposition Modeling (FDM), de uma prótese de mão articulada em peça única, gerada a partir de um modelo digital em 3D. A impressão combina o uso de dois tipos de polímeros: um mais flexível, que compõe as articulações da prótese, e outro mais rígido, que dá a estrutura ao conjunto. Importante frisar que o objeto do pedido de patente não está relacionado a um produto especificamente, mas sim ao processo de fabricação. Este pode ser aplicado tanto para a produção de próteses quanto para a de órteses ou garras (EPSZTEJN, 2008).

A titularidade do referido pedido, sob avaliação pelo INPI, pertence à Fundação Universidade de Brasília (FUB), que, por meio do Centro de Apoio ao Desenvolvimento (CDT), oficialmente reconhecido como Núcleo de Inovação Tecnológica (NIT) da Universidade de Brasília (UnB), conforme Ato da Reitoria n. 882/2007, gerencia o portfólio de patentes da universidade.

A gestão dos ativos de propriedade intelectual, entretanto, exige o desembolso de taxas ao INPI, tanto relativas às patentes concedidas quanto com relação aos pedidos de patente em análise. Em que se pese a importância da ferramenta patentária para a preservação dos direitos de propriedade industrial, explicitados na Lei n. 9.610/1998 (BRASIL, 1998), o CDT encontra exigências de ordem legal, dada sua natureza jurídica pública, e restrições financeiras para a manutenção de seu portfólio de patentes.

Por um lado, a Constituição Federal de 1988 determinou que a administração pública direta e indireta, de qualquer dos Poderes da União, dos Estados, do Distrito Federal e dos Municí- 
pios, obedeça, entre outros, ao princípio da eficiência (BRASIL, 1988). Além disso, o artigo 13, $\S 1^{\circ}$, inciso VII, da Lei n. 10.973/2007, Lei de Inovação, determina que é competência do NIT "[...] desenvolver estudos de prospecção tecnológica e de inteligência competitiva no campo da propriedade intelectual, de forma a orientar as ações de inovação da ICT" (BRASIL, 2004, art. 13). Ou seja, deve-se perseguir a "[...] melhor utilização possível dos recursos públicos, de maneira a evitarem-se desperdícios". Infere-se, dessa maneira, que o CDT tem o dever legal de analisar continuamente seus processos e dispêndios financeiros para uma melhor utilização dos recursos públicos à sua disposição.

Nesse sentido, este trabalho tem como objetivo, pois, conduzir uma qualificação tecnológica do pedido de patente n. BR 102014029649-2, considerando o histórico do pedido, o tempo decorrido de sua proposta e o estado da técnica dessa tecnologia no cenário brasileiro e mundial, de maneira a orientar as ações de inovação do CDT/UnB.

O trabalho reveste-se de importância ímpar não apenas como fonte de informação ao CDT para auxiliar na gestão adequada de seu portfólio de ativos intangíveis, permitindo um posicionamento de mercado adequado à relevância da patente, mas, sobretudo, para trazer à luz o panorama que envolve uma tecnologia de significativo impacto social.

\section{Metodologia}

Para a realização da busca por documentos patentários, foi utilizada a base PatentScope aplicando-se a combinação das palavras-chave "hand" e "prosthe*", juntamente com o operador booleano "AND" no campo de título e resumo. Também se utilizou a base patentária da Organização Mundial da Propriedade Intelectual (OMPI), ou, em inglês, World Intellectual Property Organization (WIPO), a Web of Science, aplicando-se as palavras-chave "hand" AND "prosthe*" em título e resumo. A estratégia de busca restringiu-se aos pedidos de patente apresentados a partir de 2001. Dessa maneira, pode ser verificado se o pedido de patente mantém a característica de novidade. Os resultados são apresentados na Tabela 1.

Tabela 1 - Disposição de estratégias de pesquisa USTPO (Pedidos de patente)

\begin{tabular}{lcc} 
& Combinação DE PALAVRAS-CHAVE & OcorRêNCIAS \\
$\mathbf{1}$ & "Prosthe\$" AND "hand" & $\mathbf{2 9 . 2 3 9}$ \\
$\mathbf{3}$ & "Additive manufacturing" AND prosthe\$ & $\mathbf{8 8 8}$ \\
$\mathbf{4}$ & "Additive manufacturing" AND prosthe\$ AND hand & $\mathbf{4 4 2}$ \\
$\mathbf{5}$ & "Additive manufacturing" AND prosthe\$ AND hand ANDNOT dental & $\mathbf{2 6 9}$ \\
\hline
\end{tabular}

Fonte: Elaborada pelos autores deste artigo (2019)

O inventor caracteriza o processo como composto de duas fases principais: modelagem da prótese e sua impressão tridimensional. Por esse motivo, foram elencadas palavras representativas dessas fases e do resultado final para comporem a busca, ou seja, aquelas que representariam a prótese em si e a impressão tridimensional com o método Modelagem por Fusão e Deposição: "prosthesis", "prótese", "hand", "mão", "manufacturing", "3d printer" e "addit". As palavras e 
suas variações foram utilizadas tanto para o mapeamento patentário quanto para a pesquisa documental. Com os resultados de ambos, foi possível obter informações suficientes para definir a maturidade tecnológica e comparar o estado da técnica atual com aquele verificado quando da apresentação do pedido de patente.

A análise de maturidade e prontidão tecnológica - Technology Readiness Level (TRL) - do pedido em tela foi aferido com base nas diretrizes estabelecidas pela National Aeronautics and Space Administration (NASA). Os níveis de prontidão tecnológica consistem de uma medição para apoiar avaliações da maturidade de uma determinada tecnologia, o que permite também comparar a maturidade entre diferentes tipos de tecnologia (MANKINS, 1995).

Para a análise de mercado foi conduzido um levantamento mercadológico por meio da plataforma de busca no banco de dados de importação e de exportação Comex Stat, do Ministério da Indústria, Comércio Exterior e Serviços (MDIC). O objetivo consistiu em delimitar rotas tecnológicas e movimentação de entrada e saída de produtos em território nacional, obtendo-se, dessa maneira, a identificação de variáveis mercadológicas relevantes. Para fins de viabilidade mercadológica, ademais, fez-se necessária a ponderação de potencial inovador da tecnologia e sua originalidade exigida em direito patentário, bem como possíveis cenários de risco. Todas as informações foram incluídas na análise SWOT descrita para a continuação. Para a realização dessa consulta, delimitou-se o período entre janeiro de 2008 e dezembro de 2018, bem como foi aplicado o filtro para produtos referente ao mercado de próteses em geral, conforme prevê Nomenclatura Comum do Mercosul (NCM). Como resultado, foram obtidos os dados gerais de exportação e de importação em Valor Free On Board (FOB) (US\$).

Por fim, a análise Strengths, Weaknesses, Opportunities and Threats (SWOT), ou Forças, Oportunidades, Fraquezas e Ameaças (FOFA), foi realizada com base nas informações coletadas nas buscas patentária e documental, além de obter informações advindas da classificação de maturidade da tecnologia. Os pontos fortes e as oportunidades foram considerados fatores positivos para a manutenção do pedido de patente no portfólio de ativos da UnB, enquanto os pontos fracos e as ameaças consistiram em indicadores de que os gastos com a manutenção do pedido de patente não deveriam ser mantidos, ou seja, fatores negativos.

\section{Resultados e Discussão}

Os resultados serão apresentados a seguir para embasar a discussão sobre a melhor forma de inclusão na tecnologia no mercado. $\mathrm{O}$ trabalho foi divido em tópicos para facilitar a discussão dos resultados.

\subsection{Mapeamento Tecnológico}

A presente prospecção tem como objeto um pedido patentário que visa à proteção industrial de um processo de fabricação de estruturas articuladas pela utilização de tecnologia de impressão tridimensional que combina polímeros de natureza rígida e flexível por meio de um processo denominado Fused Deposition Modeling (FDM) para a confecção de estruturas funcionais e flexíveis na aplicação de próteses, órteses ou garras. A tecnologia foi depositada junto ao INPI pela modalidade de proteção de pedido de patente de invenção, devendo, portanto, obedecer 
aos requisitos da novidade, da atividade inventiva e da aplicação industrial. Além disso, há que se ressaltar que se trata ainda de pedido de patente e não de uma patente já concedida, e que existem ainda alguns trâmites internos pelos quais o pedido de patente passará, desde a sua data de depósito até a sua efetiva análise pelo INPI, podendo ocorrer a sua efetiva concessão. Entre os trâmites estão a publicação do pedido de patente a partir do $18^{\circ}$ mês, o início da obrigação de pagamento de anuidade a partir do $25^{\circ}$ mês e o pedido de exame a partir do $36^{\circ}$ mês, contados da data de depósito (ARAÚJO et al., 2019).

Assim, buscou-se, desde logo, a caracterização do perfil dos principais depositantes constatados pelas estratégias escolhidas, a fim de estabelecer similaridades com os inventores do documento patentário aqui prospectado, verificando suas respectivas áreas de atuação e modelos de negócio, traçando possíveis paralelos e fonte de dados.

A pesquisa inicial realizada na base PatentScope utilizou combinação das palavras-chave "hand" e "prosthe *", juntamente com o operador booleano "AND" no campo de título e resumo. Obteve-se a ocorrência de 222 resultados, com 53 documentos patentários na China, 42 nos Estados Unidos, 34 no Sistema Internacional de Patentes (PCT) e 17 pelo Instituto Europeu de Patentes, conforme se verifica por meio do Gráfico 1.

Gráfico 1 - Principais países depositantes - PatentScope - Palavras-chave "hand" AND "prosthe*" em título e resumo

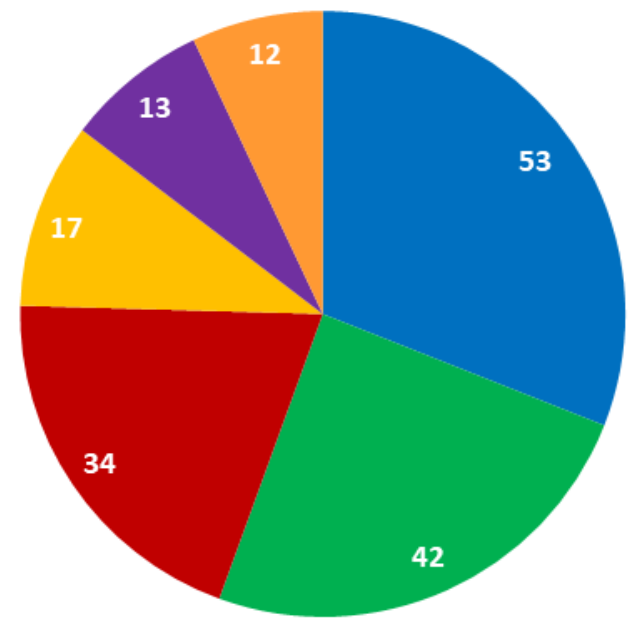

- China

- Estados Unidos da América

$\because \mathrm{PCT}$

Instituto Europeu de Patentes (IEP)

- República da Coreia

घ Federação Russa

Fonte: Elaborado pelos autores deste artigo (2019)

Segundo a mesma busca, a principal ocorrência no campo "inventor" é do autor Gregor Puchhammer, com o total de 35 documentos patentários, seguida pelos autores Arthur David Dyck, Brent Taylor Jarvis, Edwin Kay Iversen, Harold Hume Sears e Jeff Robert Welch, cada um deles com três documentos patentários. Sendo assim, Puchhammer Gregor aparece como o principal inventor na área de próteses de mãos. A plataforma Linkedin (2019) registra que Gregor Puchhammer é detentor de título de doutorado na área de inovação e inclui a citação do termo austríaco "Maschinenbau \& Betriebstechnik", que, traduzido para o português, signi- 
fica engenharia mecânica. O site APA-OST (HOFER, 2016) publicou uma matéria informativa sobre inovações em tecnologias de engenharia hidráulica, citando Gregor Puchhammer como um dos inventores da empresa de engenharia "WOGRO", sediada em Lins, capital industrial da Alta Áustria.

Em matéria jornalística publicada pelo site Gtt Healthcare (HEALTHCARE, 2016), a respeito do mercado de órteses e próteses, constata-se que $80 \%$ dos profissionais ligados ao processo inventivo são pequenos e médios empreendedores, fato este que encontra ressonância em casos como o de Gregor Puchhammer, o principal inventor depositante. Cabe lembrar que o pedido de patente do presente trabalho de prospecção pertence a professores inventores da Fundação Universidade de Brasília (FUB), isto é, uma situação aparentemente análoga aos casos aqui destacados.

Conforme aponta o Gráfico 2, a estratégia com os termos "hand AND prosthe e resumo apresentou pessoas físicas e jurídicas, sendo a pessoa jurídica Ottobock a depositante majoritária.

Gráfico 2 - Principais pessoas jurídicas depositantes - PatentScope - Palavras-chave "hand" AND "prosthe" em título e resumo

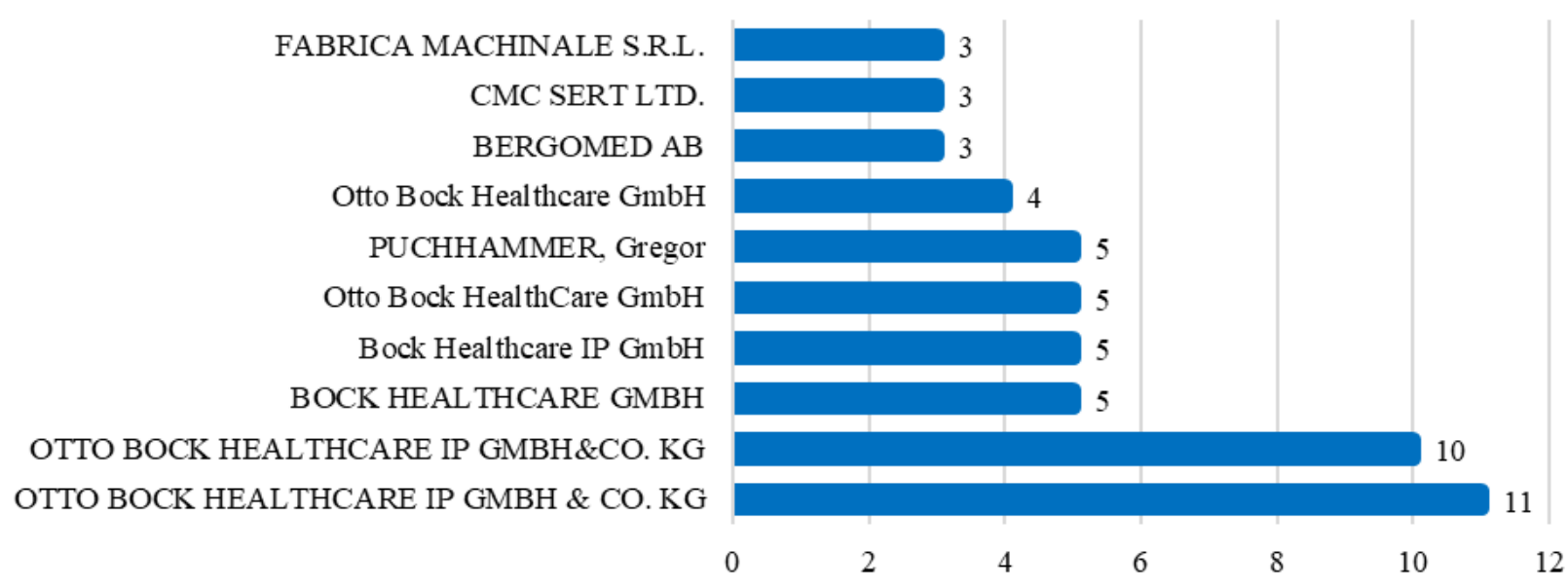

Fonte: Elaborado pelos autores deste artigo (2019)

Observa-se que as principais cinco ocorrências referem-se à empresa Ottobock Healthcare ou algumas de suas filiais. A Ottobock é uma empresa alemã especializada em próteses e órteses, sendo, ademais, mundialmente reconhecida em ambiente inovativo de tecnologias assistivas e com profícua atuação na área, com representação por franquia no mercado brasileiro (OTTOBOCK, 2019) e potencial interessado na tecnologia prospectada.

Outro fator relevante que pode ser observado por meio da busca realizada no PatentScope refere-se ao aumento de documentos patentários nos últimos anos, conforme se verifica no Gráfico 3. 
Gráfico 3 - Evolução anual do número de documentos patentários - PatentScope - Palavras-chave "hand" AND "prosthe*" em título e resumo

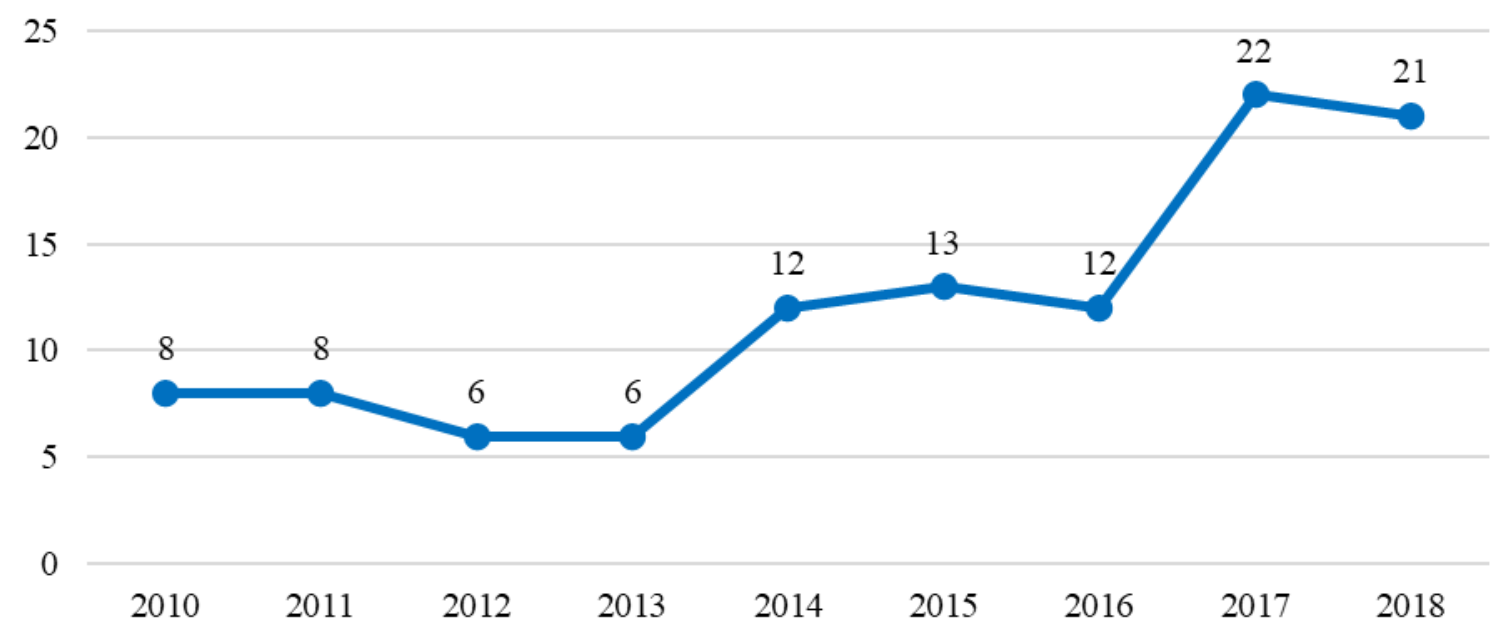

Fonte: Elaborado pelos autores deste artigo (2019)

Com o objetivo de traçar um paralelo entre as produções de documentos patentários e o número de produções científicas, utilizou-se a base Web of Science empregando-se as mesmas palavras-chave utilizadas na busca por documentos patentários realizada no PatentScope. Nessa busca, foram encontrados o total de 3.168 publicações científicas, conforme se verifica no Gráfico 4.

Gráfico 4 - Evolução anual do número de produções científicas - Web of Science - Palavras-chave "hand" AND "prosthe*" em título e resumo

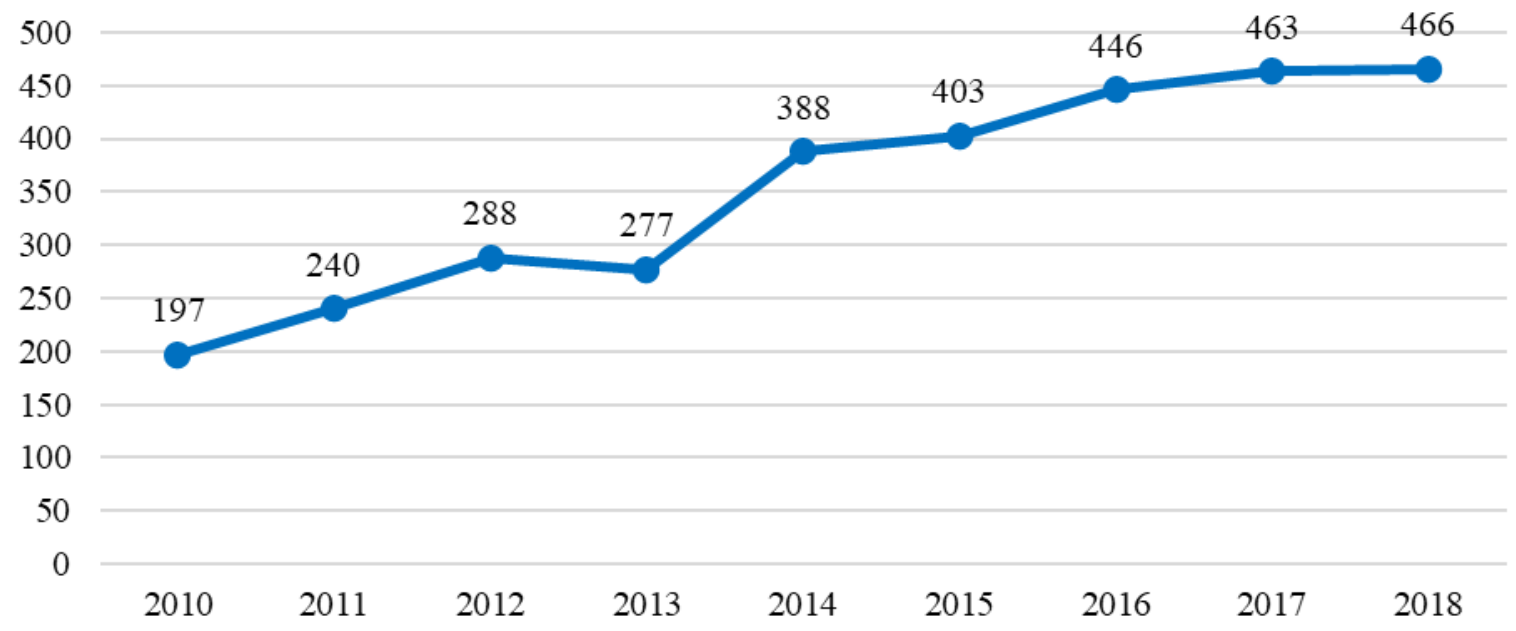

Fonte: Elaborado pelos autores deste artigo (2019)

Percebe-se, ao observar o Gráfico 4, que os dados se comportam de modo ascendente, com oscilação positiva acentuada nos anos de 2013 e 2014, fenômeno possivelmente relacionado à popularização das impressoras tridimensionais que possibilitaram o ingresso de profissionais de manufatura com menor restrição financeira. Interessante ressaltar que é perceptível, nesse sentido, alguma similaridade com o gráfico referente aos aspectos quantitativos de documentação patentária (Gráfico 3). 
Com relação ainda aso dados obtidos por meio do PatentScope, pode-se identificar os principais códigos referentes à Classificação Internacional de Patentes (CIP). Obteve-se 213 ocorrências da CIP A61F que se refere a filtros implantáveis nos vasos sanguíneos; próteses; dispositivos que promovem desobstrução ou previnem colapso de estruturas tubulares do corpo; dispositivos ortopédicos, de enfermagem ou anticoncepcionais; fomentação; tratamento ou proteção dos olhos ou ouvidos; ataduras, curativos ou almofadas absorventes; estojos para primeiros socorros: braços ou mãos artificiais ou suas partes (OMPI, 2019). A descrição detalhada da Classificação Internacional de Patentes A61F pode ser melhor entendida analisando-se a Tabela 2 .

Tabela 2 - Descrição da Classificação Internacional de Patentes (CIP) da tecnologia

\begin{tabular}{|c|c|}
\hline Código & DESCRIÇÃo \\
\hline A & Necessidades humanas \\
\hline A61 & Ciência médica ou veterinária; higiene. \\
\hline A61F & $\begin{array}{l}\text { Filtros implantáveis nos vasos sanguíneos; próteses; dispositivos que promovem } \\
\text { desobstrução ou previnem colapso de estruturas tubulares do corpo, por } \\
\text { exemplo, stents; dispositivos ortopédicos, de enfermagem ou anticoncepcionais; } \\
\text { fomentação; tratamento ou proteção dos olhos ou ouvidos; ataduras, } \\
\text { curativos ou almofadas absorventes; estojos para primeiros socorros. }\end{array}$ \\
\hline A61F 2/00 & $\begin{array}{l}\text { Filtros implantáveis nos vasos sanguíneos; Próteses, i.e. substitutos } \\
\text { artificiais ou substituições de partes do corpo; Mecanismos para conectá- } \\
\text { los ao corpo; Dispositivos que promovem desobstrução ou previnem } \\
\text { colapso de estruturas tubulares do corpo, por exemplo, stents (como } \\
\text { artigos cosméticos, ver as subclasses pertinentes, por exemplo, perucas, } \\
\text { peças de cabelo, A41G 3/00, A41G 5/00, unhas artificiais A45D 31/00; } \\
\text { próteses dentárias A61C 13/00; materiais para próteses A61L 27/00; } \\
\text { corações artificiais A61M 1/10; rins artificiais A61M 1/14) [2006.01]. }\end{array}$ \\
\hline A61F 2/54 & - Braços ou mãos artificiais ou suas partes [2006.01]. \\
\hline
\end{tabular}

Fonte: Elaborada pelos autores deste artigo (2019)

Considerando que o pedido de patente foi depositado em 27/11/2014 e que em seu relatório descritivo do estado da técnica tomou por base duas patentes concedidas nos Estado Unidos da América, optou-se por realizar, em complementação à análise dos dados disponíveis nas demais bases de patentes anteriormente descritas, uma busca de anterioridade na base do Escritório Americano de Patente e Marcas (USPTO, do inglês United States Patent and Trademark Office). O objetivo dessa busca consistiu em obter evidências sobre o estado da técnica para determinar se a invenção, objeto do pedido de patente em análise, teve sua tecnologia desenvolvida e apropriada naquele país.

Após a realização da estratégia de busca descrita na metodologia, relacionada aos pedidos de patente constantes da linha 4 da Tabela 1, que apresentou 269 resultados, foi realizada uma análise qualitativa em detalhes do conteúdo de cada documento e se chegou a três pedidos de patente cujos conteúdos assemelham-se ao caso em estudo, conforme se verifica na Tabela 3. 
Tabela 3 - Pedidos de patente no USTPO com tecnologia semelhante ao pedido brasileiro

\section{Pedido N.}

20180353308

20170049583

20160207112

\section{Título}

Digital to Definitive Orthotic and Prosthetic Device

Manufacturing System and Method

Multi-Grasp Prosthetic Hand

Additive Manufacturing of Tiled Objects

Fonte: Elaborada pelos autores deste artigo (2019)

Dos três pedidos de patente listados na Tabela 3, destaca-se o de número 20180353308, depositado em 2 de fevereiro de 2016 pelo inventor Michael e Tompkins e que tem como titular depositante a empresa Hanger Inc., com sede na cidade de Austin, Texas (EUA). Sob o título Sistema e Método Digital Definitivo de Fabricação de Dispositivos Ortóticos e Protéticos (Digital to Definitive Orthotic and Prosthetic Device Manufacturing System and Method), o referido pedido de patente consiste em um método para produzir próteses personalizadas, dispositivos ortóticos e médicos pela impressão tridimensional ou técnicas de manufatura aditiva. Inicialmente, um membro residual ou outra parte do corpo de um paciente é escaneada e analisada. As medidas e as características resultantes são usadas para projetar um dispositivo personalizado para o membro residual, a partir do uso de vários materiais diferentes. Por exemplo, o dispositivo personalizado pode usar um primeiro material para uma estrutura e um segundo material para um revestimento, em que o primeiro material é mais rígido do que o segundo material. $\mathrm{O}$ dispositivo personalizado é fabricado usando-se uma impressora tridimensional que é capaz de imprimir e de unir vários materiais diferentes ao mesmo tempo.

A descrição do pedido americano encontra muita similaridade ao brasileiro. Adicionalmente, ao se realizar uma comparação entre as reivindicações de ambos os pedidos, verifica-se que as do pedido americano englobam todas as sete reivindicações do pedido brasileiro e apresenta, ainda, outras adicionais, mostrando-se mais completa e detalhada.

A empresa Hanger Inc., fundada há mais de 155 anos por James Edward Hanger, primeiro amputado acima do joelho da Guerra Civil Americana, é especializada na fabricação de próteses e órteses e tem mais de 4.900 empregados. Apesar de centenária, possui apenas três patentes concedidas e dez pedidos em análise pelo USPTO, todos depositados entre 2005 e 2018, o que mostra que há uma estratégia muito seletiva e restrita para o depósito de patentes (HANGER, 2019).

Dessa maneira, pela pesquisa conduzida na base de dados do USPTO, é possível verificar fortes indícios de que a tecnologia objeto do pedido de patente brasileiro permanece com as características de novidade e de utilidade, dado que, mesmo nos Estados Unidos, país desenvolvido e com forte tradição em matéria patentária, permanece com interesse de empresas que fabricam próteses.

\subsection{Análise da Prontidão Tecnológica}

Conforme citado anteriormente, sob o escopo de sopesar o grau de prontidão da tecnologia prospectada, usou-se o método denominado Technology Readiness Level (TRL). Trata-se do renomado sistema de medição, a partir de uma métrica sistemática, para classificar a maturidade 
de determinada tecnologia, bem como em cotejo entre diversas tecnologias (ARAÚJO et al., 2018). Esse método estipula níveis de descrição de graus de prontidão tecnológica, sendo o primeiro deles o TRL1, isto é, o grau inicial de desenvolvimento, que envolve pesquisas basilares. O último degrau seria o TRL9, momento de finalização da tecnologia, que comumente ocorre junto às chamadas incubadoras, aceleradoras e parques tecnológicos. Além disso, trata-se aqui das questões de comercialização e de transferência de tecnologia (QUINTELLA, 2017).

O nível de maturidade pode, ainda, ser determinado a partir de indicadores de fácil obtenção, como a busca por similar já existente, pesquisa em publicações científicas e mapeamento patentário (RIBEIRO, 2018 ), dados estes coletados no presente trabalho.

Conforme descreve a redação do pedido de patente em análise, trata-se de processo para confecção de próteses articuladas com variações possíveis, encontrando-se ainda em fase de prototipagem. Mesmo que a tecnologia tenha superado a fase laboratorial, carece, pois, de verificação como produto final, certificado e disponível para comercialização. Adicionalmente, verifica-se, pelos dados obtidos na busca de publicações científicas, que a tecnologia em estudo faz parte de uma linha de pesquisa consolidada. Essas características indicam, portanto, o nível TRL4, isto é, denominado "technology development". Tal nível já comporta a divulgação do produto para interessados em licenciamentos que viabilizem uma situação real de mercado (ANDRADE, 2016).

\subsection{Análise de Mercado}

Este subtópico dedica-se a uma análise do mercado nacional de importação e de exportação de próteses no Brasil. Vale frisar que a tecnologia prospectada apresenta como atrativo a manufatura de baixo custo. De acordo com a matéria intitulada Gestão em saúde: Analisando o mercado de próteses, uma prótese de joelho custeada em aproximadamente $\mathrm{R} \$ 2.000,00$ (dois mil reais) chega ao consumidor por mais de $\mathrm{R} \$ 18.000,00$ (dezoito mil reais), sendo que $87 \%$ do acréscimo, segundo o sítio, não representam valor agregado ao produto em si. $\mathrm{O}$ uso do termo genérico "mercado de próteses ou órteses", mormente com referências financeiras, diz respeito a um complexo sistema de negócios em que a manufatura em si das próteses, de acordo com as informações aludidas, não representaria o custo majoritário (MATTOZINHOS, 2016).

Por outro prisma, entretanto, pode-se inferir que, em um mercado no qual os custos que não agregam valor ao produto sejam majoritários, uma manufatura mais barata se faz extremamente importante, principalmente quando se pensa em um público-alvo com limitações aquisitivas mais ostensivas e em possível parceria com o poder público. Ao observar a Tabela 4, é possível notar as informações a respeito da análise de custos do mercado de prótese.

Tabela 4 - Análise de custos do mercado de próteses

$\begin{array}{cccc}\text { Categoria } & \text { VAlOR } & \text { Preço De Venda } & \text { Operadora } \\ \text { Custo de produto } & \mathrm{R} \$ 2.096,00 & 16,12 \% & 11,41 \% \\ \text { Seguro, Frete e desembaraço } & \mathrm{R} \$ 335,00 & 2,58 \% & 1,82 \% \\ \text { Custo operacional } & \mathrm{R} \$ 3.770,00 & 29,00 \% & 20,53 \% \\ \text { Tributos sobre venda } & \mathrm{R} \$ 455,00 & 3,50 \% & 2,48 \%\end{array}$




$\begin{array}{cccc}\text { Categoria } & \text { ValoR } & \text { Preço De Venda } & \text { Operadora } \\ \text { Remuneração médica } & \mathrm{R} \$ 3.500,00 & 26,92 \% & 19,06 \% \\ \text { Comissão vendedor } & \mathrm{R} \$ 520,00 & 4,00 \% & 2,83 \% \\ \text { Margem distribuidor } & \mathrm{R} \$ 2.324,00 & 17,88 \% & 12,66 \% \\ \text { Preço de venda para hospital } & \mathrm{R} \$ 13.000,00 & 100,00 \% & 70,80 \% \\ \text { Margem Hospital } & \mathrm{R} \$ 3.900,00 & \mathrm{NA} & 21,24 \% \\ \text { Tributo } & \mathrm{R} \$ 1.462,00 & \mathrm{NA} & 7,96 \% \\ \text { Preço pago pela operadora } & \mathrm{R} \$ 18.362 .00 & \mathrm{NA} & 100,00 \%\end{array}$

Fonte: Mattozinhos (2016)

Realizou-se um levantamento de dados referentes ao mercado nacional de importação e exportação de próteses pelo Brasil, levando-se em consideração os dados fornecidos pelo Ministério da Indústria, Comércio Exterior e Serviços (MDIC). Utilizou-se o banco de dados de importação e exportação Comex Stat. Para a realização dessa consulta, delimitou-se o período entre janeiro de 2008 e dezembro de 2018, bem como foi aplicado o filtro para produtos referentes ao mercado de próteses em geral, conforme Nomenclatura Comum do Mercosul (NCM). Como resultado, foram obtidos os dados gerais de exportação e de importação em Valor Free On Board (FOB) (US\$), conforme mostra o Gráfico 5.

Gráfico 5 - Mercado brasileiro de exportação e importação de próteses - Valor FOB (US\$) - NCMs 90211110, 90211120, 90211190, 90212900, 90213040, 90213080, 90213030, 90211999 e 90213091

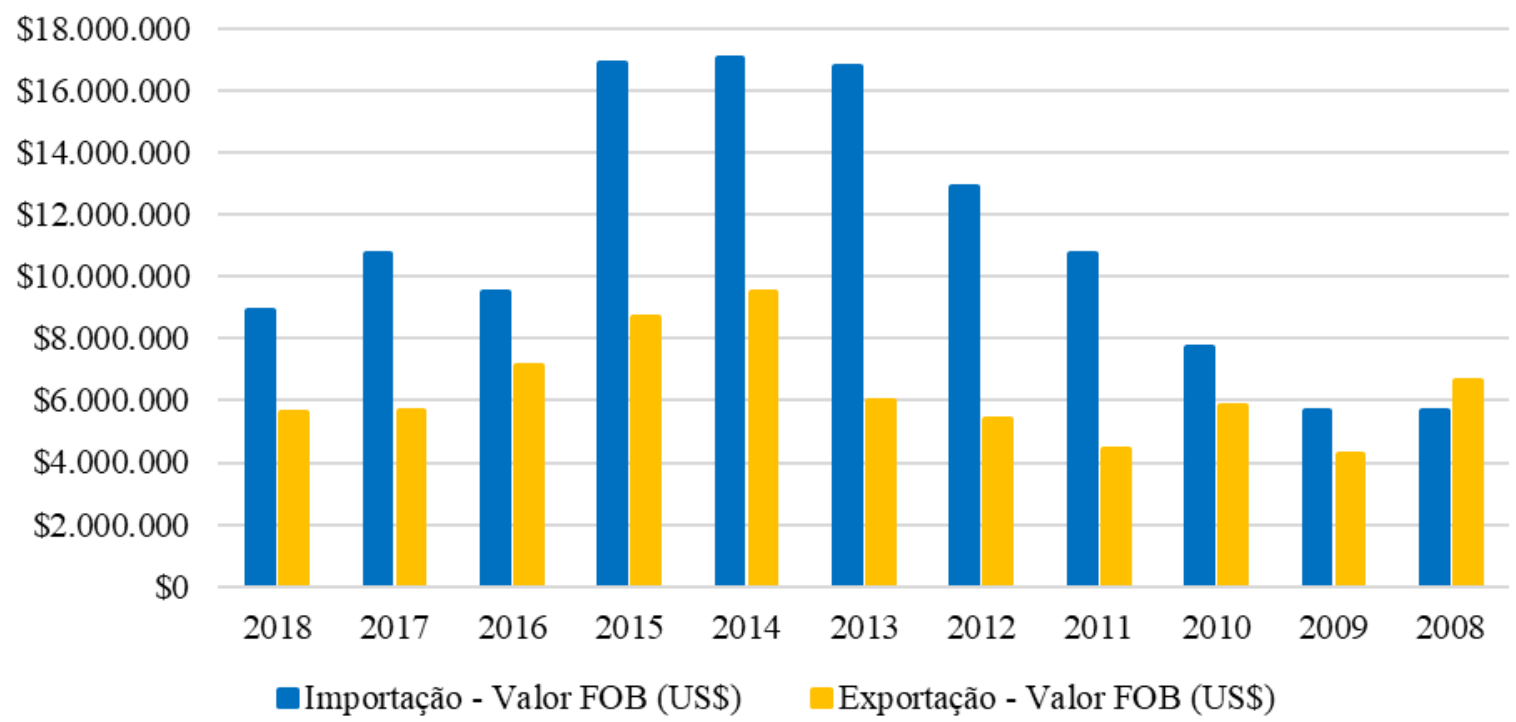

Fonte: Elaborado pelos autores deste artigo (2019)

Verifica-se pelo Gráfico 5 que o mercado nacional de próteses é baseado na importação, fato mais significativo entre os anos de 2011 a 2013. Ocorreu, ainda, um forte aumento desse tipo de mercado entre os anos de 2011 a 2015, cujos valores de importação chegaram a mais de 16 milhões de dólares americanos. Ocorreu uma forte queda, tanto no mercado de exportação quanto no de importação a partir de 2016. Deve-se ressaltar, exceto no ano de 2018, as 
importações de próteses pelo Brasil foram sempre superiores às exportações, podendo indicar uma forte carência na produção de próteses no mercado interno. Além disso, constatou-se que, nos últimos dez anos, o Brasil movimentou cerca de 190 milhões de dólares com o mercado geral de exportação e de importação de próteses.

\subsection{Análise SWOT}

A partir dos dados obtidos na análise do mercado de próteses no Brasil, nas buscas patentárias e documentais, assim como em razão das características da tecnologia objeto do pedido de patente em estudo, foi possível construir a matriz SWOT apresentada no Quadro 1, que elenca, em seus pontos fortes e oportunidades, as razões para se manter o pedido de patente no portfólio de patentes da FUB.

\section{Quadro 1 - Matriz SWOT}

\begin{tabular}{|c|c|}
\hline \multicolumn{2}{|c|}{ MATRIz SWOT } \\
\hline FATORES POSITIVOS & FATORES NEGATIVOS \\
\hline Pontos Fortes & Pontos Fracos \\
\hline $\begin{array}{c}\text { - Baixo custo de produção proporcionado } \\
\text { pelo processo de produção. } \\
\text { - O processo é de uma prótese articulada em } \\
\text { uma peça única (diferencial no mercado). } \\
\text { - Maturação Tecnológica permite } \\
\text { licenciamento pelo mercado: TRL } 4 \\
\text { - Utilização de Tecnologia 3D de fácil acesso e baixo custo. } \\
\text { - Impacto social positivo, com possibilidade } \\
\text { de atender à população de baixa renda. } \\
\text { - Baixo custo de manutenção da patente } \\
\text { junto ao INPI (R } \$ 118,00 \text { ao ano). }\end{array}$ & $\begin{array}{l}\text { - Patente protegida somente no Brasil. } \\
\text { - Produto não passou por fases posteriores às fases } \\
\text { de protótipo e não se testou a produção em escala. }\end{array}$ \\
\hline Oportunidades & Ameaças \\
\hline $\begin{array}{c}\text { - Poucas patentes de tecnologias assistivas no Brasil* } \\
\text { - Há demanda pelo produto no mercado } \\
\text { brasileiro, conforme dados do SUS. } \\
\text { - Ampla disponibilidade de matéria- } \\
\text { prima barata, plástico PLA. } \\
\text { - Alto preço de próteses importadas. }\end{array}$ & $\begin{array}{l}\text { - Tecnologias assistivas na área são mais } \\
\text { disseminadas nos EUA e China*. } \\
\text { - Patente semelhante apresentada no USTPO. }\end{array}$ \\
\hline $\begin{array}{c}\text { *Conforme resultados observados nas } \\
\text { buscas do presente estudo. }\end{array}$ & $\begin{array}{l}\text { *Conforme resultados observados } \\
\text { nas buscas do presente estudo. }\end{array}$ \\
\hline
\end{tabular}

Fonte: Elaborado pelos autores deste artigo (2019)

Em se tratando dos fatores negativos, destaca-se a proteção do ativo somente no Brasil. A patente foi depositada somente em território nacional no ano de 2014 e, por conseguinte, não mais atende ao prazo para pedido internacional junto ao Tratado de Cooperação em Matéria de Patentes (PCT), o qual estipula prazo de até 12 meses, reivindicando a prioridade.

Entretanto, pelos dados apresentados, verifica-se que os pontos fortes e as oportunidades se destacam na análise, sobretudo quando são considerados a demanda anual de próteses no Brasil e o alto preço dos produtos equivalentes importados, em contraponto ao baixo custo de produção trazido pelo processo em análise. Adicionalmente, reveste-se de importância um 
produto de baixo custo e alto impacto social, apontando para vantagens significativas na manutenção do pedido de patente no portfólio de ativos da FUB.

\subsection{Transferência de Tecnologia e Perspectivas Futuras}

Destaca-se, inicialmente, que transferência de tecnologia pode ser entendida como "[...] o processo de transferência de descobertas científicas de uma organização para outra, com o objetivo de desenvolvimento e comercialização adicionais" (AUTM, 2018). Isso posto, e conforme avaliação do nível de maturidade da tecnologia em questão, pode-se verificar que esta encontra-se atualmente em TRL4. Nesse sentido, faz-se necessário buscar parcerias para celebração de contratos de transferência de tecnologia que visem à realização de testes ou melhoramentos a fim de aumentar o grau de maturidade da tecnologia, buscando-se tornar possível a sua inserção do mercado.

Deve-se observar que a tecnologia estudada se refere a um pedido de patente que reivindica o processo de fabricação de próteses e o seu respectivo uso. Sendo assim, os potenciais parceiros interessados na tecnologia são os pertencentes à indústria de fabricação de próteses em si. A celebração de um Acordo de Cooperação Técnica, ou de um Contrato de Licenciamento de Uso, que tenha como objeto a validação e o melhoramento do pedido de patente junto a um parceiro que realiza processo de fabricação de próteses pode ser uma alternativa viável de transferência de tecnologia nessa etapa de desenvolvimento, uma vez que os resultados podem gerar um posterior licenciamento da tecnologia para uso e exploração comercial, ou até mesmo facilitar a obtenção de uma concretização dos aspetos referentes ao pedido de patente que precisem ser melhorados para se obter um futuro licenciamento.

Para Pimentel (2010), o Acordo de Cooperação é o instrumento jurídico utilizado principalmente pela Administração Pública para formalizar vínculo para contribuição mútua entre os partícipes que tenham interesses e condições recíprocas ou equivalentes, de modo a realizar um propósito comum, voltado ao interesse público. Dessa maneira, caberia utilizar como alternativa a celebração de uma parceria para que uma instituição, que possivelmente terá interesse futuro na tecnologia, faça parte, nesta etapa, da continuidade do desenvolvimento tecnológico. Tal estratégia pode gerar, futuramente, tanto a transferência da tecnologia em si quanto a proteção de novas tecnologias ou melhoramentos que vierem a ser desenvolvidos no âmbito do Acordo. Faz-se primordial, portanto, buscar uma aproximação da academia com a indústria de produção de próteses a fim de gerar novas oportunidades, seja para dar continuidade às pesquisas no campo das próteses no âmbito da universidade, seja para dar ensejo a concretização de um processo de transferência de tecnologia.

\section{Considerações Finais}

Este trabalho conduziu, no cenário brasileiro e internacional, uma prospecção tecnológica do pedido de patente afeto ao processo de fabricação de prótese de mão articulada em peça única que tem a Fundação Universidade de Brasília como detentora. Os dados do Sistema Único de Saúde (SUS) mostram um crescimento no número de procedimentos de amputações de membros superiores e inferiores no país, o que aponta para uma possível demanda de aquisição de próteses para suprir essa necessidade. 
Por outro lado, o panorama mundial apresenta um mercado forte e concentrado para produtos de Equipamentos e Materiais Médicos, Hospitalares e Odontológicos (EMHO), no qual o segmento de órteses e próteses está inserido. Já a balança comercial brasileira apresentou, no período de 2008 a 2018, um volume significativamente maior de importações sobre as exportações, o que revela uma carência na produção de próteses em território cenário nacional.

Foi possível identificar os principais atores relacionados à pesquisa $e$ ao desenvolvimento de tecnologia na área de próteses e órteses, sendo que a empresa Otto Bock Healthcare é a líder mundial nesse segmento, apresentando mais de 30 documentos patentários depositados em diferentes países. A China e os EUA foram os países com o maior número de ocorrências de documentos patentários. Também foi possível identificar os principais pesquisadores e inventores atuantes no âmbito da pesquisa, desenvolvimento e inovação no mercado de órteses e próteses humanas.

Nesse contexto, foi possível realizar uma comparação entre os pontos fortes e as oportunidades advindas com a tecnologia em análise e os pontos fracos e ameaças do cenário. Foi possível, assim, inferir que os fatores positivos superaram consideravelmente os fatores negativos, sobretudo quando se considera que a patente proporcionará, caso utilizada comercialmente em parceria com empresa nacional, a produção de uma solução com baixo custo de aquisição e alto impacto social.

Dessa forma, conclui-se pela necessidade de se buscar firmar parcerias com os setores produtivos de próteses a fim de aumentar o grau de maturidade da tecnologia para tornar possível a sua inserção do mercado. Uma alternativa viável é a celebração de instrumentos que viabilizem uma aproximação da academia com a indústria de produção de próteses a fim de gerar novas oportunidades, seja para dar continuidade às pesquisas no campo das próteses no âmbito da universidade, seja para dar ensejo à concretização de um processo de transferência de tecnologia.

\section{Referências}

ABDI - AGÊNCIA BRASILEIRA DE DESENVOLVIMENTO INDUSTRIAL. Plataformas demonstradoras tecnológicas aeronáuticas, experiências com programas internacionais, modelagem funcional aplicável ao Brasil e importância da sua aplicação para o País. Brasília, DF: ABDI, 2014. 122p. ISBN: 978-85-61323-17-2.

ANDRADE, Marcelino Monteiro de et al. Processo de fabricação de próteses articuladas a partir da combinação de materiais rígidos e flexíveis em uma única peça. Titular: UnB. $\mathrm{BR}$ n. 102014029649-2. Depósito: 27 nov. 2014. Publicação: 31 maio 2016. Revista da Propriedade Industrial, 2016.

ARAÚJO, Lívia Pereira de et al. Avaliação tecnológica de dispositivo cicatrizante para pés diabéticos com capacidade de neoformação tecidual. Cadernos de Prospecção, Salvador, v. 11, n. 3, p. 910927, 30 set. 2018. Universidade Federal da Bahia. Disponível em: https://portalseer.ufba.br/index. php/nit/article/view/27101. Acesso em: 3 ago. 2019.

ARAÚJO, Lívia Pereira de et al. Direito patentário brasileiro. In: SANTOS, Wagna Piler Carvalho dos. Conceitos e aplicações em propriedade intelectual. Salvador: Fortec, 2019. Cap. 4. p. 236297. (v. II). Disponível em: http://www.profnit.org.br/wp-content/uploads/2019/04/PROFINIT-SerieConceitos-e-Aplica\%C3\%A7\%C3\%B5es-de-Propriedade-Intelectual-Volume-II-1.pdf. Acesso em: 3 ago. 2019. 
AUTM - ASSOCIATION OF UNIVERSITY TECHNOLOGY MANAGERS (Estados Unidos). About Technology Transfer: AUTM's Technology Transfer Video. [2018]. Disponível em: https://www.autm. net/autm-info/about-tech-transfer/about-technology-transfer/. Acesso em: $1^{\circ}$ maio 2018.

BRASIL. Lei n. 9.610, de 19 de fevereiro de 1998. Altera, atualiza e consolida a legislação sobre direitos autorais e dá outras providências. Brasília, DF, Presidência da República, 1998. Disponível em: http://www.planalto.gov.br/ccivil_03/leis/19610.htm. Acesso em: 10 abr. 2019.

BRASIL. Lei n. 10.973 de 2 de dezembro de 2004. Diário Oficial da União, Brasília, DF, 12 de janeiro de 2004. Disponível em: http://www.planalto.gov.br/ccivil_03/_ato2004-2006/2004/lei/ 110.973.htm. Acesso em: 13 abr. 2019.

BRASIL. Ministério da saúde lança licitação para registro de preços de órteses e próteses. Brasília, DF, $1^{\circ}$ de fevereiro de 2018. Disponível em https://portalarquivos2.saude.gov.br/images/ pdf/2018/fevereiro/01/Coletiva-Ortese-e-Protese.pdf. Acesso em: 15 de fevereiro de 2020.

EPSZTEJN, Michel et al. Evolução das próteses no Brasil: características da propriedade industrial. In: ENCONTRO NACIONAL DE ENGENHARIA DE PRODUÇÃO, 28. Rio de Janeiro, 2008. Anais [...]. Rio de Janeiro, 2008. Disponível em: http://www.abepro.org.br/biblioteca/enegep2008_tn_ sto_076_536_11662.pdf. Acesso em: 10 abr. 2019.

HANGER, Inc. About Hanger. 2019. Austin, Texas, EUA. Disponível em: http://www.hanger.com/ about/Pages/default.aspx. Acesso em: 9 ago. 2019.

HEALTHCARE, Gtt. Mercado de órteses e próteses: OPME no Brasil. 2016. Disponível em: http:// gtthealthcare.com.br/blog/index.php/mercado-de-orteses-e-proteses-no-brasil-opme/. Acesso em: 12 abr. 2019.

HOFER, Michael. WOGRO: Österreichische Innovation revolutioniert Wassertechnik. 2016.

Disponível em: https:/www.ots.at/presseaussendung/OTS_20161110_OTS0025/wogro-

oesterreichische-innovation-revolutioniert-wassertechnik-bild. Acesso em: 12 abr. 2019.

LINKEDIN. Gregor Puchhammer, PhD. [2019]. Disponível em: https://at.linkedin.com/in/gregorpuchhammer-phd-7525a410. Acesso em: 12 abr. 2019.

MANKINS, Roberto. Manual sobre o uso da Escala TRL/MRL. 1995. Disponível em: https://cloud. cnpgc.embrapa.br/nap/files/2018/08/EscalaTRL-MRL-17Abr2018.pdf. Acesso em: 14 abr. 2019.

MATTOZINHOS, Anderson. Gestão em saúde: analisando o mercado de próteses. 2016.

Disponível em: https://geekonomics.com.br/2016/05/gestao-em-saude-analisando-mercado-proteses/. Acesso em: 14 abr. 2019.

OMPI - ORGANIZAÇÃO MUNDIAL DA PROPRIEDADE INTELECTUAL. Classificação

Internacional de Patentes (CIP). 2019. Disponível em: http://ipc.inpi.gov.br/classifications/ipc/ipcp $\mathrm{ub} /$ ?notion $=$ scheme\&version $=20200101 \&$ symbol $=$ none\&menulang $=$ en\&lang $=$ en $\&$ viewmode $=\mathrm{f} \&$ fipcpc $=$ no\&showdeleted $=$ yes\&indexes $=$ no\&headings $=$ yes $\neg e s=$ yes\&direction $=02 n \&$ initial $=$ A\&cwi $\mathrm{d}=$ none $\&$ tree $=$ no\&searchmode $=$ smart. Acesso em: 9 ago. 2019.

OTTOBOCK. Site Oficial. [2019]. Disponível em: https://www.ottobock.com.br/. Acesso em: 12 abr. 2019.

PATENTSCOPE. [Base de dados - Internet]. [2018]. Disponível em: https://patentscope.wipo.int/ search/pt/search.jsf. Acesso em: 12 abr. 2019. 
PEIXOTO, Alberto Monteiro et al. Prevalência de amputações de membros superiores e inferiores no estado de Alagoas atendidos pelo SUS entre 2008 e 2015. Fisioterapia e Pesquisa, [s.l.], v. 24, n. 4, p. 378-84, 2017. Disponível em: http://www.scielo.br/pdf/fp/v24n4/2316-9117-fp-24-04-378.pdf. Acesso em: 12 abr. 2019.

PIMENTEL, Luiz Otávio. Manual Básico de Acordos de Parceria de PD\&I. Porto Alegre: Edipuc RS, 2010. 277p.

QUINTELLA, C. M. A revista cadernos de prospecção e os níveis de maturidade de tecnologias (TRL). Cadernos de Prospecção, Fortaleza, v. 10, n. 1. 2017.

ROCHA, Gabriela. Ministério da Saúde lança licitação para registro de preços de órteses e próteses. Agência Saúde, últimas notícias, 2018. Disponível em: http://www.saude.gov.br/noticias/ agencia-saude/42429-ministerio-da-saude-lanca-licitacao-para-registro-de-precos-de-orteses-eproteses. Acesso em: 11 abr. 2019.

STAT, Comex. Comex Responde. 2019. Disponível em: http://comexstat.mdic.gov.br/pt/sobre. Acesso em: 14 abr. 2019.

USPTO - UNITED STATES PATENT AND TRADEMARK OFFICE. [Base de dados - Internet]. [2019]. Disponível em: https://www.uspto.gov/patents-application-process/search-patents. Acesso em: 12 abr. 2019.

WIPO - WORLD INTELLECTUAL PROPERTY ORGANIZATION. PatentScope. Base de dados internet. [2019]. Disponível em: https://patentscope.wipo.int/search/en/search.jsf. Acesso em: 12 abr. 2019.

\section{Sobre os Autores}

\section{Victor Seabra Dornas}

E-mail: victor.seabra@gmail.com

Bacharel em Direito.

Endereço profissional: Campus Universitário Darcy Ribeiro, Edifício CDT, Sala do PROFNIT/UnB, Asa Norte, Brasília, DF. CEP: 70904-970.

\section{Magna Pinheiro Pessoa}

E-mail: magnapinpe@gmail.com

Pós-graduada MBA em Marketing e comunicação pelo Banco do Brasil. Pós-graduada MBA em Gestão Empresarial com Ênfase em Tecnologia e Inovação. Aluna especial do Mestrado em Propriedade Intelectual e Transferência de Tecnologia para a Inovação (PROFNIT/UnB).

Endereço profissional: Campus Universitário Darcy Ribeiro, Edifício CDT, Sala do PROFNIT/UnB, Asa Norte, Brasília, DF. CEP: 70904-970.

\footnotetext{
Alan Elvis Lima

E-mail: alanelvis@hotmail.com; magnapinpe@gmail.com

Pós-Graduado em Gestão Estratégica de Negócios.

Endereço profissional: Campus Universitário Darcy Ribeiro, Edifício CDT, Sala do PROFNIT/UnB, Asa Norte, Brasília, DF. CEP: 70904-970.
} 


\section{Lívia Pereira de Araújo}

E-mail: livia.pa90@gmail.com

Mestre em propriedade intelectual e transferência tecnologia para inovação.

Endereço profissional: Campus Universitário Darcy Ribeiro, Edifício CDT, Sala do PROFNIT/UnB, Asa Norte,

Brasília, DF. CEP: 70904-970.

\section{Grace Ferreira Ghesti}

E-mail: ghesti.grace@gmail.com

Doutora em Química.

Endereço profissional: Campus Universitário Darcy Ribeiro, Edifício CDT, Sala do PROFNIT/UnB, Asa Norte, Brasília, DF. CEP: 70904-970.

\section{Paulo Gustavo Barboni Dantas Nascimento}

E-mail: pbarboni@unb.brDoutor em Química.

Pós-Doutor em Farmacologia pela Faculdade de Medicina de Ribeirão Preto (FMRPUSP).

Endereço profissional: Campus Universitário Darcy Ribeiro, Edifício CDT, Sala do PROFNIT/UnB, Asa Norte, Brasília, DF. CEP: 70904-970. 